\title{
0 que pode um autor ensinar aos escritores? uma reflexão sobre corpo e mediação nas oficinas de escrita criativa
}

\author{
Geruza Zelnys Almeida \\ Universidade de São Paulo, São Paulo, Brasil \\ zelnys@hotmail.com
}

\begin{abstract}
Resumo: O artigo se propõe a refletir sobre a autoria e o lugar do escritor nas oficinas de escrita criativa, a partir de um componente pedagógico, mediador na relação de movimento e fluxo entre os participantes, que tem no corpo seu espaço privilegiado de agenciamentos. A argumentação é inspirada e se sustenta na leitura do texto "O autor como produtor", de Walter Benjamin, em diálogo com outros teóricos que o seguiram pensando a mesma questão.
\end{abstract}

Palavras-chave: autoria; pedagogia; corpo; performance; oficinas de escrita criativa.

\section{cena 1:}

Depois daquilo, ela já não me convidava para entrar. Eu entrava assim mesmo. Também já não contava as histórias: tinha eu de adivinhá-las.

\section{cena 2:}

Hoje, as histórias se contam. Enquanto escrevo

\section{um artigo:}

Em 1934, Walter Benjamin escreveu "O autor como produtor", ensaio no qual está a afirmação que motiva minha discussão: "Um autor que não ensina nada aos escritores não ensina nada a ninguém"1. A assertiva, lida há muito tempo e abandonada num caderno de anotações para o doutorado, ficou gravada na memória e, agora, ressoa em mim, pois implica um componente ideológico que o diferencia entre os debatedores basilares da questão da autoria: Barthes (1968), Foucault (1969) e Derrida (1972). Há no seu entendimento de autoria um vínculo com a pedagogia que não poderia passar despercebido, uma vez que também está fortemente pontuado em outros ensaios, em especial n' "O narrador", de 1936, no qual aborda a narrativa do ponto de vista da transmissão da experiência.

O meu interesse de autora se amplia na atuação como mediadora em oficinas de escrita criativa, logo, em contato direto com escritores e numa função que tem 
sido objeto de reflexão no meu pós-doutoramento sobre as potencialidades provocativas, educativas e terapêuticas desses encontros de criação literária ${ }^{2}$. Portanto, minha questão é o que eu - como autora e mediadora - posso ensinar aos escritores? Ou ainda, a autoria é algo que se ensina? Se sim, como? Mais importante: quais os riscos de se perder ou até eliminar as possibilidades de autoria tratando-a como objeto de uma didática?

Primeiramente, é preciso mostrar a diferença que se inscreve no pensamento de Benjamin (1987, p. 128-129), pois, segundo minha leitura, há uma distância que separa o autor - que seria uma espécie de produtor de produtores, pois, com a consciência de seu engajamento revolucionário contra uma ordem estabelecida e dada - dos demais "escritores rotineiros", que seguem uma tendência e, por isso, apenas reafirmam o aparelho de produção, sem contudo, confrontá-lo. No ensaio, não se mascara o forte direcionamento ao proletariado e à arte revolucionária e afinada com a prática: o autor deve usar o aparelho de produção contra ele mesmo, desnudando e melhorando a estrutura do sistema, diferentemente da inversão vivida pelos escritores que são usados pelo meio de produção, pois não superam "as contradições que acorrentam o trabalho produtivo com a inteligência", ou ainda, não conseguem derrubar "as barreiras que separam duas forças de competência - a intelectual e a material - erigidas para separá-las". Para Benjamin (1987, p. 134), a autoria, portanto, somente é fruto do progresso técnico quando ele está ligado ao avanço político, por isso necessariamente quando inscrita no gesto de traição: "num comportamento que o transforma de fornecedor do aparelho de produção intelectual em engenheiro que vê sua tarefa na adaptação desse aparelho aos fins da revolução proletária".

Quase cem anos nos separam do pensamento desse autor e o que vemos na literatura é, por um lado, a era da reprodutibilidade técnica levada à máxima potência, a explosão do mercado editorial e a facilidade de publicação que convida à profissionalização do escritor; por outro, o desejo genuíno de escritura e, em certo sentido contrariando "O narrador", desde os anos 1970 a inclinação à escrita da experiência com forte teor testemunhal (SELLIGMAN-SILVA, 2003). Nesse contexto, vemos o surgimento de uma tendência em território brasileiro que são as oficinas de escrita criativa como resposta à demanda e como suporte para a formação desses (futuros) escritores. Escritores que, como eu, estão entrando em contato com a própria voz e buscando aperfeiçoá-la ao mesmo tempo em que se preparam para, de todo modo, alimentar a indústria do livro, que fabrica todo dia algumas centenas de escritores, sem, contudo, se preocupar com a produção de leitores. Isso parece bastante desmotivador, ainda mais se nos perguntarmos com franqueza e coragem: estamos escrevendo para quem?

Se a resposta à essa pergunta for transitiva e tiver no leitor seu ponto de chegada - um leitor em tudo ideal porque não sabemos se existe e onde se esconde - corremos o risco de "escrever para" e não "escrever por". "Escrever para" concentra a sedução de seguir uma tendência para agradar a um público imaginário em detrimento dos impulsos (desejo, necessidade, pulsão, ideal) que nos levam a "escrever por". Isso é muito significativo para mim, pois penso no risco de que esses discursos de "formação" ou "aperfeiçoamento" de escritores, um dia, venham a se 
institucionalizar e, com isso, abafar o caráter livre, processual, dinâmico e vivo que tem (ou deveria ter) a criação e a construção de conhecimentos nesses espaços.

Como professores, sabemos da dificuldade em manter a potência criativa e criadora nos espaços educativos, que são lugares em que os discursos tendem à institucionalização, eliminando a negatividade da linguagem que, ao se dizer, não se diz. Por isso, não é impossível que esses espaços alternativos também possam ter sua potência destruída justamente quando da efetivação daquilo que, a princípio, parece ser seu objetivo: formar escritores. De modo algum, acredito que isso já aconteça, embora não raro ouço depoimentos de participantes frustrados por terem frequentado oficinas configuradas como extensão da sala de aula, com avaliações do tipo certo ou errado interferindo ativamente na criação. ${ }^{4}$ Isso acende uma luz sobre os riscos que rondam tudo que é da ordem do ingovernável - neste caso o corpo da criação - e assombra-me que, futuramente, com a crescente popularização das oficinas, possa eu mesma vir a ocupar o lugar de agente dessa despotencialização. Assim, em última instância, minha questão é sobre como proceder em nome daquilo que acredito: o escritor-autor.

Como escritora, costumava buscar respostas para [minha] autoria nas reflexões sobre a autonomia do texto em Roland Barthes; ou na função-autor como princípio de agrupamento, unidade e origem do discurso em Foucault; ou em noções como assinatura e traço em Derrida, ou até numa espécie de entidade criminosa como eu mesma já sustentei certa vez (ALMEIDA, 2013). Todavia, o trabalho com a mediação me obrigou a voltar a Benjamin e ao protagonismo de certa fisicalidade que sustenta a caneta ou que imprime os dedos fortemente sobre as letras no teclado. A ênfase no "elemento gestual", reafirmado e afinado na leitura que dele faz Agamben (2007, p. 55), coloca o autor na posição de um gesto, de uma força ou energia vital que, se desaparece depois do texto escrito, não deixa dúvida que já esteve lá:

\footnotetext{
O autor marca o ponto em que uma vida foi jogada na obra. Jogada, não expressa; jogada, não realizada. Por isso, o autor nada pode fazer além de continuar, na obra, não realizado e não dito. Ele é o ilegível que torna possível a leitura, o vazio lendário de que procedem a escritura e o discurso. O gesto do autor é atestado na obra a que também dá vida, como uma presença incongruente e estranha, [...] como um laço, ele volta cada vez a reatar o fio que soltou e desapertou, assim também o gesto do autor garante a vida da obra unicamente através da presença irredutível de uma borda inexpressiva.
}

Evidentemente, pode-se argumentar que todos os demais estudiosos acabaram por dizer isso a seu modo, mas é no tempo destinado a esse gesto e na ideia de sua continuidade no outro que me irmana, agora, de Walter Benjamin. Isso porque, se Agamben, assim como os outros teóricos que mencionei acima, parte do texto para falar de um gesto presente nele de modo espectral, Benjamin se dirige do autor ao texto, pois se concentrará na duração desse gesto de produção que liga, indissoluvelmente, corpo, corpos e corpus num sentido muito mais coletivo do que individual, já que se demora (demeure, de-mora) no presente da autoria ou na autoria do presente. 


\title{
o corpo que não...
}

\begin{abstract}
Um autor que não ensina nada aos escritores não ensina nada a ninguém. Assim, é decisivo que a produção tenha um carácter de modelo, capaz de, em primeiro lugar, levar outros produtores à produção e, em segundo lugar, pôr à sua disposição um aparelho melhorado. E esse aparelho é tanto melhor quanto mais consumidores levar à produção, numa palavra, quanto melhor for capaz de transformar os leitores ou espectadores em colaboradores. (BENJAMIN, 2006, sem anotação de página, grifos do autor)

Um escritor que não ensina outros escritores não ensina ninguém. O caráter modelar da produção é, portanto, decisivo: em primeiro lugar, ele deve orientar outros produtores em sua produção e, em segundo lugar, precisa colocar à disposição deles um aparelho mais perfeito. Esse aparelho é tanto melhor quanto mais conduz consumidores à esfera da produção, ou seja, quanto maior for sua capacidade de transformar em colaboradores os leitores ou espectadores. (BENJAMIN, 1987, p. 129, grifos do autor)
\end{abstract}

Mais do que nunca ${ }^{5}$, pensar com Benjamin o lugar de certa educação e colaboração para a autoria é fundamental nesses tempos em que a literatura começa a ser objeto de ensino também nos espaços não-formais de aprendizagens. Sabemos o que se ensina nas escolas e universidades: não a literatura, mas o que foi feito dela como movimentos, procedimentos, especificidades estéticas, técnicas autorais, cânones, formas de representação, questões sobre crítica e recepção etc.; nesses espaços, estamos sempre transitando entre uma pedagogia da literatura $e$ uma literatura pedagógica. Mas, e nas oficinas de escrita, o que se deve ensinar se a criatividade é algo que somente pode ser estimulada? Qual o risco de repetir os mesmos ensinamentos desse fora da literatura àqueles que querem estar dentro dela?

Parece que Benjamin responde acima, quando diz que um autor deve levar outros escritores a produzirem, além de ofertar-Ihes um aparelho "melhorado", pois já confrontado pela autoria. Mas, melhorado com o que senão com o singular também exigido na produção autoral do escritor que vem? Note-se que a construção colaborativa é, aqui, de fundamental importância no processo descrito pelo teórico, pois esse contato entre autor e leitor é que permitirá o fluxo e a troca pedagógica que corre em duas vias, visto que por se tratar de um espaço agenciado por escritores essas funções sejam, a todo o momento, compartilhadas. No entanto, a intervenção do autor deve necessariamente ser completada pelo escritor para que ele possa também se autorizar como autor entrando em "confronto positivo" com o aparelho de produção. Trata-se, portanto, de um gesto realizado a quatro mãos.

No contexto das oficinas, entendo como aparelho de produção tanto o mercado livreiro que se beneficia, inclusive, da imagem do escritor, como a plataforma texto, aparelho pelo qual deslizam tanto as autorias quanto as assim chamadas tendências. Desse modo, é sobre esses aparelhos que o escritor deve girar encarando-os nos olhos a fim de transformá-los; ou, segundo as palavras do 
próprio Benjamin (referindo-se ao teatro épico de Bertold Brecht com o qual exemplifica sua teorização), o autor deve "interromper a ação" para dá-la a ver pelo leitor e/ou espectador.

Até aqui, penso que a imagem de corpo como materialidade já esteja delineada, pois esses giros e ações sobre o aparelho não podem ocorrer sozinhos, mas somente a partir de um corpo que os comporte. $\mathrm{E}$, seguindo essa direção, arrisco uma tentativa de resposta à questão colocada no título deste artigo: um autor só pode ensinar ao escritor seu corpo portador de gestos de autoria.

\title{
cena 3:
}

Ela ria e trinta e um segredos mostravam os dentes entre os dentes que eram seus.

\section{... acaba nunca}

\begin{abstract}
Observe-se de passagem que não há melhor ponto de partida para o pensamento que o riso. As vibrações físicas produzidas pelo riso oferecem melhores ocasiões para o pensamento do que as vibrações da alma. $O$ teatro épico só é luxuriante nas ocasiões que oferece para o riso. (BENJAMIN, 1987, p. 134).
\end{abstract}

Vale dizer mais uma vez que a autoria em Benjamin é um pensamento que incorpora o corpo: são movimentos, gestos, vibrações físicas, riso, ações que estimulam a reflexão e desnudam a engenharia de um aparelho de produção. Minha interpretação para esse aparelho plural - mercado e obra - então se expande para o próprio autor ele mesmo, aparelho corpóreo que é o meio de produção de seu corpus escrito. Sob essa ótica, autor seria aquele que se volta para si mesmo e se reconfigura, se "melhora", ou seja, incorpora-se de si para quebrar as barreiras que separariam suas forças intelectivas e materiais. Não à toa, Benjamin elege o teatro épico de Brecht para se referir a esse corpo de ação que ouso, agora, aproximar do "corpo-consciência" em José Nuno Gil (2003, p. 14, grifos do autor): estado alcançado no ato criativo quando a consciência é impregnada pelo corpo inaugurando uma "espécie de avesso da intencionalidade", onde "toda a consciência não é 'consciência de', [e] o objeto não surge 'em carne e osso' diante do sujeito; pelo contrário, a consciência do corpo é a impregnação da consciência pelo corpo".

Trata-se de ousadia porque, se em Benjamin, esse corpo de ação tem uma destinação ou propósito final (uma revolução proletária), em Gil o destino é uma abertura tal que se lança sem garantias a não ser à experiência da própria infinitude, contagiando os demais corpos do espaço, abrindo-os também. É, sim, um movimento revolucionário, ou melhor, composto de micro-movimentos revolucionários porque da ordem do "molecular" para usar um termo deleuziano; no entanto, aberto aos devires sejam quais sejam: "a dança compõe-se de sucessões de micro-acontecimentos que transformam sem cessar o sentido do movimento" (GIL, 2001, p. 66). Já em Benjamin (1987, p. 129), o devir é a revolução e o que não 
é revolução é tendência, "condição necessária, mas não suficiente, para o desempenho da função organizatória da obra. Esta exige um comportamento prescritivo, pedagógico, por parte do escritor". Note-se que a insuficiência da obra de tendência está no fato de não possuir o caráter modelar que, por sua vez, deve ser o objeto de uma pedagogia: "o caráter modelar da produção é, portanto, decisivo" (1987, p. 129). Para mim, o mais interessante nesse fragmento é que essa obra de caráter modelar, aqui, é aquela mesma que se volta contra um modelo. Desde aí meu interesse em pensar a autoria com Benjamin focando não os resultados, mas o momento mesmo de sua produção - na plenitude dos gestos - porque sinto que, apesar desses giros todos, ele não consegue se desvencilhar dos modelos estéticos sem, com isso, criar uma abertura para os direitos estéticos.

Enfim, se há distâncias entre os dois pensadores de linhagens diferentes, as semelhanças são inegáveis quanto à inscrição dos afetos no corpo da obra e daqueles que giram em torno dela: seus autores e leitores ${ }^{6}$. A afetividade aparece, em ambos, como pressuposto de autoria e, por isso, me fascina porque o trabalho com a mediação também me coloca no lugar privilegiado da criação em seu momento inaugural: uma produção em tudo provisória é partilhada por corpos que a afetam e são afetados por ela. Esse primeiro momento da escritura está muito vinculado à performance, pois a produção incorpora o corpo que a produziu e funda, com ele, uma visibilidade tal que produz novas autorias nos demais escritores afetados e contagiados pelo corpo-corpus partilhado nisso que passa a ser um novo "espaço de agenciamentos" delineado nas oficinas de escrita criativa.

Essa ordem de ideias me leva a pensar, então, que aquilo que um autor ensina é seu corpo - corpus - de afetividades, produzindo nos escritores os estímulos e perturbações necessárias para que percebam também os próprios corpos e, com isso, possam entrar em "confronto positivo" consigo mesmos. Esse encontros, especialmente de autoconhecimento, possibilitam um processo de autopoiesis $^{7}$ à medida que as respostas - físicas e intelectivas - vão se autoproduzindo como singularidades e, se dependentes da perturbação meio ${ }^{8}$, ainda assim autossuficientes porque são absolutamente pessoais e respondem, a cada um, ao seu modo.

Nesse contexto de produção e autoprodução, observa-se a importância de se deter na $v^{9} z^{9}$ enquanto materialidade primeira e lugar de uma performance para delinear as pedagogias plurais que convivem no espaço da criação literária. Esclareço que voz aqui não se aplica apenas à manifestação sonora ou à fala, mas associa-se à performatividade inscrita em sua relação com a escuta e com a presença que se concretiza e se renova na escritura. Presença, performance, voz e escuta me ajudam a dar forma conceitual à experiência vivenciada nos cursos de criação literária, onde a autopoiesis necessita de todo empenho do corpo (físico, emocional e intelectual) para se realizar sem buscar acabamento numa didática convencional de ensino-aprendizagem.

Muito além do aspecto sonoro, nesta discussão, a voz adquire conotação de força concentradora de múltiplas gestualidades que desembocam na autoria. Ritmo, entonação, silêncios, movimentos corporais e temporalidades ${ }^{10}$ são vivenciados em todo processo de criação, mas, quando a autoria não se efetiva como singularidade 
aberta à singularidade do outro, essas forças se dispersam na obra. Meschonnic (2006) fala muito apropriadamente de uma "ética poética" vinculada ao ritmo (pela ondulação, pulsação, respiração) como produtora do sujeito. Assim, se o ritmo é algo que nunca conhecemos antecipadamente, ele só acontecerá no ato mesmo de sua produção, portanto, sua perpetuação na escritura dependerá de uma respiração em conjunto com a do leitor para manter o texto como organismo vivo.

Talvez estejamos falando, aqui, dos "elementos mais minúsculos do comportamento" que Benjamin (1987, p. 132) apontou como fundamentais para a constituição da autoria, pois ligados à experiência mais profunda da criação. Diz ele em "Sobre o conceito da história", ensaio de 1940: "com efeito, toda experiência profunda deseja, insaciavelmente, até o fim de todas as coisas, repetição e retorno, restauração de uma situação original, que foi seu ponto de partida." (p. 224). Qual seria essa situação original se não aquela em que o verbo irrompe despretensioso como voz e gesto? A pergunta vai ao encontro dos fragmentos autobiográficos dispostos em "Rua de mão única" (1987, p. 11), nos quais, mais de uma vez, o pensador enfatiza que a verdadeira literatura não pode ficar refém de "molduras literárias", pois

a atuação literária significativa só pode instituir-se em rigorosa alternância de agir e escrever, tem de cultivar as formas modestas; que correspondem melhor a sua influência em comunidades ativas que o pretensioso gesto universal do livro, em folhas volantes, brochuras, artigos de jornal e cartazes.

A provisoriedade e a mínima pretensão de se tornar um escritor de livros, destacadas por Benjamin, parecem ser também condição necessária ao bom andamento e aproveitamento de uma oficina de escrita criativa: criar não para ser livro, mas para recriar-se antes de tudo. Publicar livros é uma realidade e consequência natural para os escritores, mas que isso não seja o determinante do processo; ao invés disso, o processo seria ele mesmo o objetivo e o risco de abertura ao infinito. Ao escritor só é feita uma exigência: a reflexão. Mas, o mandamento de "refletir sobre sua posição no processo produtivo" coloca o escritor necessariamente em contato com o corpo e seus movimentos necessários para entender as espacialidades e os agenciamentos que gravitam nesse meio pelo qual corre o processo de produção.

\section{tradução e autoria}

“Um escritor que não ensina outros escritores não ensina ninguém”.

Benjamin escreve essa frase assim, em itálico, e, por algum motivo, lembrome do filme "O livro de cabeceira" (GREENAWAY, 1996), mais exatamente do momento no qual a protagonista passa a ter uma relação ativa com a escritura: ela que, até então, oferecia seu corpo para receber a tinta, o pincel e a escritura, passa a inscrever sua caligrafia sobre as peles de outros corpos. Essa mudança, marcada pelo gesto de uma nova narração que se faz a partir de si, parece também estar 
presente nas traduções do original de Benjamin que seria totalmente inacessível para mim. Entre um gesto e outro de tradução, uma sutil transformação marca o sujeito da frase que, em um dos seus (e dos meus) textos, era o autor: "Um autor que não ensina nada aos escritores não ensina nada a ninguém". Agora no lugar de autor, Benjamin diria apenas "um escritor" e é como se algo precisasse ser recuperado na minha leitura de uma proposição já marcada e transformada pela autoria: um escritor que ensina escritores só pode ser autor.

O autor seria aquele que ensina ao outro a (sua) autoria. Relação colaborativa e necessária. "Uma mão não pode escrever em si mesma" é o verso de Sei Shonagon escrito sobre os dedos daquele corpo que era o jovem monge do Livro dos Segredos no filme de Greenaway. A autoria é algo que se constrói a quatro mãos - mais o demais dos corpos.

O processo que levou do escritor ao autor, ou do autor incorporado ao escritor, no (meu) texto de Benjamin, além de todas as marcas corpóreas mencionadas por ele e a atitude reflexiva requerida por essa densa parceria, recebeu ainda a marca visual pesando - literalmente por se tratar do itálico - sobre a inscrição de um pensamento sobre um corpo de afetos: corpus que se expande em outro: este que agora "é" com aquele. Não é preciso mais ler a palavra autor porque ela está ressoando na frase - como gesto e voz - pelo empenho do corpo que energizou essa escritura: corpo erógeno de ideias que se volta sobre si mesmo, aparelho de produção que é, e se estimula na produção de novos sentidos e virtualidades.

\section{Cena 4}

Duas mulheres e já

éramos

muitas

Finalizo esta breve argumentação, reafirmando que nas oficinas de escrita criativa vivenciamos experiências plurais de pedagogias e, desde aí, a necessidade de se refletir sobre esse saber sensível produzido nesses espaços alternativos que, sendo também constituídos por signos educativos, difere-se daquele produzido na educação formal. A importância desse questionamento contínuo é para não nos deixarmos emparedar por didáticas que acabem replicando o ensino tradicional, com suas aulas teóricas ou meramente informativas, que pode fazer com que um desejo de criação, destinado a ser voz e autoria, fracasse em meio ao barulho discursivo.

Não é novidade que quem busca um curso de criação literária o faça porque gosta de escrever e/ou tem o desejo de se tornar escritor. Coincidentemente, essa é uma das coisas que ouvimos dizer dos alunos que ingressam nas Letras, onde o desejo de ler/escrever ficção/poesia é engolido pela teoria e o ensino sistemático da língua. Há, portanto, que, ao menos nesses espaços alternativos de construção de saberes sensíveis, esse desejo de autoria seja potencializado a fim de que uma voz, em tudo original apesar de toda e qualquer influência, se manifeste. Como fazer isso 
se, entre muitas práticas, está a de conhecer e "imitar" certos procedimentos realizados por autores canônicos? Ou como valorizar uma voz que não há ainda outra para figurar como medida? Mais ainda, como não calar essa autoria?

Penso que essas questões e as outras que foram surgindo ao longo do texto já estão respondidas pela proposta de se pensar o corpo como produto e produtor de afetos, estimulado pela presença incorporada da fisicalidade na consciência. $E$, sendo assim, as oficinas de criação literária podem (e devem) ser o lugar onde signos educativos provoquem uma experiência singular de subjetividade ativa. Do contexto benjaminiano para a atualidade na qual nos afastamos, cada vez mais, da relação com esse corpo de afetos em favor de uma racionalidade abstrata que não poupa nada e ninguém, da teorização exacerbada de todos os eventos que constroem o corpo da história e que, por tudo isso, nos distancia da carnalidade da experiência, qualquer ato sensível e consciente que tenha na inscrição do corpo e pelo corpo sua fonte e foz será uma forma de revolução.

\title{
Cena final
}

"Coce para ler, arranhe para entender."11

\begin{abstract}
This article proposes a discussion about authorship and the writer's place in creative writing workshops. Our point of start is the pedagogical component that mediates the movement and flow among the participants, who have in their own body their agency space. Our arguments are inspired and based on the text "The author as producer" by Walter Benjamin; we also search to establish a dialog with other theoretical thinkers that worked with this problem.
\end{abstract}

Keywords: authorship, pedagogy, body, performance, creative writing workshop.

\section{Referências bibliográficas}

AGAMBEN, Giorgio. O autor como gesto. In: AGAMBEN, Giorgio. Profanações. São Paulo: Boitempo, 2007.

ALMEIDA, Geruza Zelnys de. "Um pensamento de/do autor". In: Revista FronteiraZ, n. 11, dez/2013. Disponível em http://revistas.pucsp.br/index.php/fronteiraz/article/view/17219/13092 Acesso em 18/04/2016.

BARTHES, Roland. "A Morte do Autor". In: BARTHES, Roland. O Rumor da Língua. São Paulo: Martins Fontes, 2004.

BENJAMIN, Walter. Magia e técnica, arte e política. Ensaios sobre literatura e história da cultura. Obras escolhidas, vol. I, São Paulo: Ed. Brasiliense S/A, 1987. 
Rua de mão única. Obras escolhidas, vol. II, São Paulo: Ed. Brasiliense S/A, 1987.

DERRIDA, Jacques. "Assinaturas". In: Margens da filosofia. Campinas: Papirus, 1991.

FOUCAULT, Michel. "O que é um autor?". In. O que é um autor?. Coleção Passagens. Lisboa: Vega, 1992.

GIL, José Nuno. Movimento Total - o corpo e a dança. Lisboa: Relógio d’Água, 2001.

- "Abrir o corpo". Palestra proferida no Simpósio Corpo, Arte e Clínica. Porto Alegre, Universidade Federal do Rio Grande do Sul - UFRGS, PPG em Psicologia Social e Institucional, 2003.

GREENAWAY, Peter. The Pillow Book. 126 min. Paris: Dis Voir, 1996.

MATURANA, Humberto e VARELA, Francisco. De máquinas e seres vivos. Autopoiese, a Organização do Vivo. Porto Alegre: Artes Médicas, 1997.

MATURANA, Humberto. Cognição, ciência e vida cotidiana. Belo Horizonte, MG: Ed. UFMG, 2001.

MESCHONNIC, Henri. Linguagem: ritmo e vida. Belo Horizonte: Fale/UFMG, 2006.

SACKS, Oliver. Um antropólogo em Marte. São Paulo: Companhia das Letras, 2006.

SELIGMANN-SILVA, Márcio (org.) História Memória Literatura. Campinas: Editora da Unicamp, 2003.

Recebido em 22/04/2016

Aprovado em 10/05/2016

\section{Notas}

${ }^{1}$ Esclareço um fato interessante com relação a esse artigo: quando me propus a escrevê-lo
baseei-me num fichamento que, conforme minhas anotações, compõe o livro A
modernidade - Obras escolhidas de Walter Benjamin, traduzido por João Barrento (Lisboa,
Assírio \& Alvim, 2006). Foi a partir dessa estranha relação de diferença entre autor e escritor
que delineei as relações que gostaria de estabelecer no meu texto. No entanto, tive de voltar
ao livro (esse mesmo que tenho agora em minhas mãos e que foi traduzido por Sergio Paulo
Rouanet) e minha surpresa foi ver que a diferença, tão importante para meus argumentos, 
se dissolvia na seguinte tradução: "Um escritor que não ensina outros escritores não ensina ninguém". Então me peguei com um problema de origem: como desprezar a tradução primeira, inaugural em minha mente, em favor de outra que apagava justamente o fundamental para minha indagação? Resolvi esse problema de ficção da origem com um gesto de autoria: mantenho a frase ecoando como me veio e sigo com os fragmentos retirados dessa segunda leitura - agora palpável em formato livro impresso - e, no momento propício para isso, retomarei os resultados desse gesto.

${ }^{2}$ Este artigo é parte da minha pesquisa de pós-doutorado intitulada: "De como voar com as asas quebradas. Ou a autopoiesis e as potencialidades provocativas, educativas e terapêuticas das oficinas de escrita criativa", sob a supervisão do Prof. Dr. Alexandre Filordi de Carvalho, no departamento de Filosofia da Educação na UNIFESP - Guarulhos/SP, financiada por bolsas da CAPES e do CNPq.

3 Defino o escritor rotineiro como o homem que renuncia, por princípio, a modificar o aparelho produtivo a fim de romper sua ligação com a classe dominante, em benefício de novas formas de organização e vida em sociedade. Afirmo ainda que uma parcela substancial da literatura de esquerda não exerceu outra função social que a de extrair da situação política novos efeitos, para entreter o público. Isso me traz ao tema da "Nova Objetividade". Ela lançou a moda da reportagem. A questão é a seguinte: a quem serviu essa técnica? (BENJAMIN, 1987, p.128).

${ }^{4}$ Além da mediação que faço no CLIPE - Curso Livre de Preparação do Escritor, na Casa das Rosas/SP, também idealizei e criei o Curso de Escrita Curativa, no qual utilizo uma metodologia sustentada pela análise desse processo e pela teoria sobre a qual venho me debruçando na pesquisa. É com base na experiência realizada com várias turmas que sigo com a argumentação.

${ }^{5}$ Escrevo esse artigo em meio ao processo de impeachment que se elabora contra a presidenta Dilma Rousseff, ouvindo os brados de uma população que toma a Avenida Paulista (São Paulo) com discursos vazios e cristalizados pela mídia. Sinto que essa realidade, no presente desta escritura, inscreve também seus ruídos no texto e, talvez, isso seja suficiente para explicar meu apelo à educação para a autoria que venho discutindo no artigo e que muito se aproxima, no meu presente, do ideal benjaminiano.

${ }^{6}$ Benjamin inclui aqui os espectadores e atores; Gil, os bailarinos.

${ }^{7} \mathrm{Na}$ minha pesquisa, trabalho com a ideia de autopoiesis a partir dos estudos dos biólogos Maturana e Varela (1997) que deram esse nome ao processo de autoprodução circular que garante a autonomia do ser vivo. A princípio, eles se detinham sobre os organismos unicelulares e a capacidade da célula de produzir-se a si mesma, recompondo continuamente seus componentes enfraquecidos, o que faz da molécula produtora, mas também produto de si mesma. Os resultados da pesquisa se estenderam a todos os seres vivos que também seriam sistemas de autopoiesis moleculares determinados e em relação com o meio, que se autoproduzem a partir das perturbações afetivas às quais estão expostos.

${ }^{8} \mathrm{~A}$ ontogenia de um ser vivo é uma deriva estrutural, na qual as mudanças estruturais que ocorrem são contingentes com as interações com o meio. Não são determinadas pelas circunstâncias do meio, mas são contingentes com elas, porque o meio apenas desencadeia no ser vivo mudanças estruturais. (MATURANA, 2001, p. 81).

${ }^{9}$ Um pensamento detido sobre a voz direciona minhas oficinas de Escrita Curativa, cujo foco é o cuidado no resgate e/ou retomada de uma voz, por vezes até desconhecida, porém criadora e criativa e, por isso, ligada ao desejo (possível ou não de ser realizar) de reeducação dos afetos. A proposta de reeducação dos afetos me surge como continuidade 
das leituras de Oliver Sacks (2006), como o conhecido "O caso do pintor daltônico", nas quais ele conta sobre os processos de readaptação dos pacientes com graves problemas neurológicos. Tomando a si e aos pacientes como seres ativos de suas transformações, Sacks destaca o quanto a doença (ou os modos da dor e do trauma) são elementos impulsionadores de transformação positiva e necessária na vida dos seres biológicos devido às adaptações do corpo aos aspectos condicionantes e limitadores do mundo. Pensar, portanto, que podemos nos reeducar tanto biológica quanto afetivamente em espaços alternativos destinados à criação, é algo que está nas bases de uma ideia libertadora de educação.

${ }^{10}$ Pela voz, a significação precede o sentido, ela o porta. As palavras estão na voz. Como a relação precede e traz consigo os termos. O que a entonação faz. Compreender, paradoxalmente, precede o sentido. (MESCHONNIC, 2006, p. 47).

11 Verso de Sei Shonagon escrito no escalpo do jovem monge do Livro dos Segredos (GREENAWAY, 1996). 